D) Check for updates

Cite this: Phys. Chem. Chem. Phys., 2017, 19, 15570

DOI: $10.1039 / c 7 c p 90113 e$

rsc.li/pccp

\section{Correction: Supramolecular influence on cis-trans isomerization probed by ion mobility spectrometry}

\author{
Izabella Czerwinska, ${ }^{\mathrm{a}}$ Alexander Kulesza, ${ }^{\mathrm{b}}$ Changmin $\mathrm{Choi}^{\mathrm{b}}$ Fabien Chirot, ${ }^{\mathrm{c}}$ \\ Anne-Laure Simon, ${ }^{b}$ Johann Far, ${ }^{a}$ Christopher Kune, ${ }^{a}$ Edwin de Pauw ${ }^{a}$ and \\ Philippe Dugourd ${ }^{\mathrm{b}}$
}

Correction for 'Supramolecular influence on cis-trans isomerization probed by ion mobility spectrometry' by Izabella Czerwinska et al., Phys. Chem. Chem. Phys., 2016, 18, 32331-32336.

The name of one of the co-authors contains a spelling mistake in the published article. "Chistopher Kune" should be listed as "Christopher Kune" as provided in the corrected author list above.

The Royal Society of Chemistry apologises for these errors and any consequent inconvenience to authors and readers.

\footnotetext{
${ }^{a}$ Mass Spectrometry Laboratory, University of Liège, Quartier Agora, Allée du Six Aout 11, B-4000 Liège, Belgium

${ }^{b}$ Univ Lyon, Université Claude Bernard Lyon 1, CNRS, Institut Lumière Matière, F-69622, Villeurbanne, France

${ }^{c}$ Univ Lyon, Université Claude Bernard Lyon 1, Ens de Lyon, CNRS, Institut des Sciences Analytiques, UMR 5280, 5 rue de la Doua, F-69100, Villeurbanne, France. E-mail: fabien.chirot@univ-lyon1.fr
} 